\title{
Fatty Acids and Other Risk Factors for Sudden Cardiac Death in Patients Starting Hemodialysis
}

\author{
Allon N. Friedman ${ }^{a}$ Zhangsheng $\mathrm{Yu}^{\mathrm{b}}$ Cheryl Denski ${ }^{\mathrm{b}}$ Hector Tamez ${ }^{\mathrm{c}}$ \\ Julia Wenger ${ }^{c}$ Ravi Thadhani ${ }^{c}$ Yong Li $^{d}$ Bruce Watkins ${ }^{d}$ \\ a Department of Medicine, Division of Nephrology, and bepartment of Biostatistics, Indiana University School of \\ Medicine, Indianapolis, Ind., 'Department of Medicine, Division of Nephrology, Massachusetts General Hospital, \\ Boston, Mass., and d Department of Nutritional Sciences, Lipid Chemistry and Molecular Biology Laboratory, \\ University of Connecticut, Storrs, Conn., USA
}

\section{Key Words}

Omega-3 · Fatty acids · Sudden cardiac death .

Hemodialysis · Incident · Risk factors · Nutrition ·

Cardiovascular disease

\begin{abstract}
Background: Little is known about risk factors for sudden cardiac death in hemodialysis patients during the high-risk first year of dialysis. We therefore undertook to identify such risk factors in a nationally representative cohort and were able to include baseline levels of blood fatty acids, some of which influence arrhythmogenicity and sudden cardiac death risk. Design: The study cohort included 100 patients who died of sudden cardiac death during the first year of hemodialysis and 300 frequency-matched controls. Using the elastic net statistical method, numerous demographic and clinical characteristics were included with baseline total serum levels for 11 major fatty acids (model 1) and with serum phospholipid fractions of these same fatty acids (model 2). Final models included only covariates that had a non-zero coefficient. Results: In model 1, serum albumin [odds ratio $(95 \% \mathrm{Cl}): 0.55$ $(0.33-0.93) ; p=0.03$ ] and total serum long-chain $n-3$ docosapentaenoic acid [0.70 (0.51-0.97); $p=0.03$ ] were inversely associated with the odds of sudden cardiac death, while the
\end{abstract}

total serum saturated fatty acid level had a direct association [1.01 (1.00-1.02); $p=0.03]$. In model 2, serum albumin and docosapentaenoic acid remained inversely associated with sudden cardiac death in a similar manner as in model 1. Pulse pressure also had an inverse association [0.96 (0.93-1.00); $p<$ 0.05]. Conclusions: Several factors, including blood content of docosapentaenoic acid and saturated fatty acids, were associated with the odds of sudden cardiac death during year one of hemodialysis. These results raise the possibility that dietary modification may reduce sudden death risk.

Copyright $\odot 2013$ S. Karger AG, Basel

\section{Introduction}

Sudden cardiac death is the single most common cause of mortality in the hemodialysis population, accounting for approximately one quarter of all deaths [1]. While the rate of sudden cardiac death in hemodialysis patients has slowly fallen in recent years along with overall mortality [1], more substantial reductions remain hampered by our limited understanding of the underlying pathophysiology and need to identify causative factors.

Over the past several years, numerous investigations performed in various dialysis populations have attempted

\section{KARGER}

E-Mail karger@karger.com

www.karger.com/ajn
(C) 2013 S. Karger AG, Basel

0250-8095/13/0381-0012\$38.00/0
Allon N. Friedman, MD

550 University Blvd.

Suite 6100

Indianapolis, IN 46202 (USA)

E-Mail allfried@iupui.edu 
to identify risk factors for sudden cardiac death [2-11]. Of these, only one [8] focused on the early period after initiation of hemodialysis when mortality risk is highest [12] and none studied a cohort that was representative of the overall US hemodialysis population. In addition, none included dietary factors such as serum fatty acids that could account for risk. This is important because several fatty acids have been associated with sudden cardiac death in the general population, each of which is modifiable by changes in dietary intake. By far the most prominent of these are long-chain $n-3$ polyunsaturated fatty acids (LCn-3 PUFA) which have been touted for their cardioprotective and anti-arrhythmic benefits. A number of large, well-designed randomized trials have reported that LCn-3 PUFA supplementation lower the risk of cardiovascular events and sudden cardiac death [13-16], though not all studies are in agreement [17-21]. In the first study of its kind, we recently demonstrated that LCn-3 PUFA are strongly, inversely, and independently associated with risk of sudden cardiac death in an incident population of hemodialysis patients [22].

To expand on this work, we endeavored to identify all independent risk factors for sudden cardiac death in a large representative cohort of US hemodialysis patients who were followed over the first year of dialysis. We were able to include blood fatty acid levels in the analysis and hypothesized that LCn-3 PUFA and perhaps other fatty acids would be among the identified associated factors.

\section{Methods}

\section{Study Population and Collection of Serum Samples}

The complete methods have been published previously [23]. All study subjects participated in the Accelerated Mortality on Renal Replacement (ArMORR) project, a nationally representative prospective cohort study of patients who initiated chronic hemodialysis at any one of over 1,000 US dialysis centers operated by Fresenius Medical Care, North America, between July 1, 2004, and June 30, 2005. 10,044 incident hemodialysis patients representing 1,056 US dialysis units were prospectively enrolled into ArMORR. ArMORR contains detailed demographic and clinical data, including comorbid conditions, laboratory results, and blood samples at the time of dialysis initiation. All clinical data were collected prospectively and entered uniformly into a central database by the patients' practitioners at the point-of-care based on medical records and physical examination. Blood samples collected for clinical care were drawn at individual dialysis units and shipped the same day on ice to Spectra East (Rockland, N.J., USA), a good clinical practice-accredited central laboratory. After blood was extracted for clinical testing, the remaining serum was immediately placed in new tubes, frozen at $-80^{\circ} \mathrm{C}$, and sent to ArMORR investigators where the samples were aliquotted and immediately stored at $-80^{\circ} \mathrm{C}$ (and subsequently liquid nitrogen). Serum fatty acids remain stable for years when stored in this manner [24]. This study was approved by the Institutional Review Board of the Massachusetts General Hospital, Boston, Mass., USA, which waived the need for informed consent.

\section{Identification of Patients Dying of Sudden Cardiac Death and} Controls

Sudden cardiac death events in ArMORR were defined as deaths occurring (1) out of hospital that were (2) identified by International Classification of Diseases (ICD)-9 diagnosis codes for 'cardiac arrest' (ICD-9: 427.5) and 'sudden death, cause unknown' (ICD-9: 798.1, 798.2, 798.9) [25]. The ICD-9 codes, frequently used to study sudden cardiac death in dialysis patients $[8,26,27]$, were documented by the subject's health care providers at the time of death on a dialysis unit mandatory discharge form. The convenience sample we studied included 100 patients who died from sudden cardiac death within 1 year of initiating hemodialysis and 300 hemodialysis patients who survived the first year of dialysis (controls) who were frequency matched by age, gender, and race in a random fashion [23]. Characteristics for each of the case and control cohorts have previously been published $[22,23]$.

\section{Laboratory Analysis}

Biochemical assays were performed at the Spectra East laboratory using standard assays as previously described [28]. Serum was used to determine fatty acid amounts in various lipid fractions in a blinded fashion at the University of Connecticut using gas chromatography and solid-phase extraction techniques [23]. Results of the fatty acid methyl ester analysis were obtained by area percentage reports and reported in weight percent. In addition to individual fatty acids, we also reported composite fatty acids as the following area percent: LCn-3 PUFA included 20:5 n-3 [eicosapentaenoic acid (EPA)] + 22:5 n-3 [docosapentaenoic acid (DPA) ] +22:6n-3 [docosahexaenoic acid (DHA)]; LCn-6 PUFA included 20:4 n-6 (arachidonic acid) + 22:4 n-6 + 22:5 n-6; saturated fatty acids included 16:0 + 18:0; monounsaturated fatty acids included 16:1 n-7 + 18:1 n-9 + 18:1 n-7, and polyunsaturated fatty acids included LCn-3 PUFA + LCn-6 PUFA.

\section{Statistical Analysis}

Patients' characteristics were summarized using mean and standard deviation for continuous variables and frequency and proportion for categorical variables. The weight percentages of fatty acids were summarized using the median (25th, 75 th percentile) due to skewed distribution. To identify the risk factors or predictors of sudden cardiac death we used the well-established LASSO (least absolute shrinkage and selection operator) type method (elastic net) [29] for variable selection in a logistic regression model with sudden cardiac death as the response variable. In contrast to the stepwise regression method, the elastic net method does not require a subjectively selected $\mathrm{p}$ value threshold and accommodates the selection of correlated covariates. We first ran a model (model 1) with 11 serum total fatty acids [monounsaturated, saturated, trans, $\alpha$-linolenic (18:2 $n-6)$, arachidonic (20:4 n-6), 22:4 $n-6,22: 5 n-6$, linoleic (18:3n-3), eicosapentaenoic (20:5 n-3), docosapentaenoic (22:5n-3), and docosahexaenoic (22:6n-3)] and the following covariates: demographics (age, gender, race, ethnicity); body mass index; diabetes as cause of end-stage renal disease (yes/no); medical problems (a history of coronary artery disease or myocardial infarction, peripheral vascular disease, stroke, 
Table 1. Baseline characteristics

\begin{tabular}{|c|c|}
\hline & $\begin{array}{l}\text { Study } \\
\text { population } \\
(\mathrm{n}=400)\end{array}$ \\
\hline Age, years & $66.4 \pm 14.1$ \\
\hline Male & $232(58.0)$ \\
\hline \multicolumn{2}{|l|}{ Race } \\
\hline Black & $124(31.0)$ \\
\hline White & $272(68.0)$ \\
\hline Other & $4(1.0)$ \\
\hline \multicolumn{2}{|l|}{ Ethnicity } \\
\hline Non-Hispanic & $352(88)$ \\
\hline Hispanic & $48(12)$ \\
\hline Body mass index & $26.2 \pm 6.8$ \\
\hline \multicolumn{2}{|l|}{ Cause of end-stage renal disease } \\
\hline Diabetes & $186(46.5)$ \\
\hline Other & $214(53.5)$ \\
\hline \multicolumn{2}{|l|}{ Comorbidities } \\
\hline Hypertension & $149(37.3)$ \\
\hline Coronary artery disease/myocardial infarction & $46(11.5)$ \\
\hline Peripheral vascular disease & $20(5.0)$ \\
\hline Congestive heart failure & $50(12.5)$ \\
\hline Atrial fibrillation & $13(3.3)$ \\
\hline Stroke & $15(3.8)$ \\
\hline \multicolumn{2}{|l|}{ Initial type of vascular access } \\
\hline First access fistula & $120(31.1)$ \\
\hline First access graft & $44(14.3)$ \\
\hline First access catheter & $211(54.7)$ \\
\hline Systolic blood pressure, $\mathrm{mm} \mathrm{Hg}$ & $142.8 \pm 23.0$ \\
\hline Diastolic blood pressure, $\mathrm{mm} \mathrm{Hg}$ & $72.6 \pm 12.4$ \\
\hline \multicolumn{2}{|l|}{ Medications } \\
\hline ACE inhibitor or ARB & $169(42.3)$ \\
\hline$\beta$-Blocker & $243(60.8)$ \\
\hline Aspirin & $129(32.3)$ \\
\hline Statin & $159(39.8)$ \\
\hline \multicolumn{2}{|l|}{ Predialysis laboratory values } \\
\hline Serum albumin, $\mathrm{g} / \mathrm{dl}$ & $3.5 \pm 0.5$ \\
\hline Serum cholesterol, mg/dl & $150.6 \pm 46.0$ \\
\hline Serum creatinine, $\mathrm{mg} / \mathrm{dl}$ & $6.1 \pm 2.6$ \\
\hline Serum ferritin, $\mathrm{ng} / \mathrm{ml}$ & $328.3 \pm 583.2$ \\
\hline Serum phosphorus, mg/dl & $4.6 \pm 1.6$ \\
\hline Serum potassium, mEq/l & $4.3 \pm 0.6$ \\
\hline Serum calcium, mg/dl & $8.4 \pm 0.8$ \\
\hline Serum PTH, pg/ml & $263.1 \pm 299.4$ \\
\hline Serum alkaline phosphatase, units/l & $100.3 \pm 71.3$ \\
\hline Serum glucose, $\mathrm{mg} / \mathrm{dl}$ & $157.8 \pm 78.5$ \\
\hline Hemoglobin, g/dl & $10.3 \pm 1.4$ \\
\hline White blood cells $\left(\times 10^{3} / \mu \mathrm{l}\right)$ & $8.4 \pm 3.3$ \\
\hline
\end{tabular}

Figures indicate means \pm standard deviations or numbers with percentages in parentheses. Reprinted with permission from reference 23 and S. Karger AG.
Table 2. Serum fatty acid levels in the study cohort

\begin{tabular}{lc}
\hline Fatty acid & Total \\
\hline Saturated & \\
$16: 0$ & $6.2(19.2,21.4)$ \\
$18: 0$ & \\
\hline Monounsaturated & $2.3(2.2,2.7 .6)$ \\
$16: 1 \mathrm{n}-7$ & $23.9(21.7,26.2)$ \\
$18: 1 \mathrm{n}-9$ & $2.3(2.2,2.6)$ \\
$18: 1 \mathrm{n}-7$ & \\
\hline Polyunsaturated & \\
Omega-6 & $28.3(26.4,30.8)$ \\
$\quad 18: 2 \mathrm{n}-6$ & $7.5(6.0,9.0)$ \\
$20: 4 \mathrm{n}-6$ & $0.5(0.4,0.7)$ \\
Omega-3 & $0.3(0.2,0.4)$ \\
$\quad 18: 3 \mathrm{n}-3$ & $0.4(0.3,0.5)$ \\
$20: 5 \mathrm{n}-3$ & $1.3(1.0,1.8)$ \\
$\quad 22: 5 \mathrm{n}-3$ & $2.0(1.6,2.5)$ \\
$22: 6 \mathrm{n}-3$ & $8.0(6.5,9.7)$ \\
\hline Long chain $\mathrm{n}-3$ & $4.0(3.3,4.7)$ \\
Long chain $\mathrm{n}-6$ & $28.0(26.8,29.2)$ \\
Long chain $\mathrm{n}-6 / \mathrm{n}-3$ & $28.2(25.5,30.8)$ \\
Saturated fatty acids & $40.9(38.0,44.3)$ \\
Monounsaturated fatty acids & \\
Polyunsaturated fatty acids & \\
\hline
\end{tabular}

Figures are medians (25th, 75th percentiles) of percent weight. Adapted with permission from reference 23 and S. Karger AG.

Table 3. Variables associated with odds of sudden cardiac death in the first year of hemodialysis in a final model ${ }^{\mathrm{a}}$ that included total serum fatty acids

\begin{tabular}{|c|c|c|c|}
\hline Variable & Coefficient & $\begin{array}{l}\text { Odds ratio } \\
(95 \% \mathrm{CI})^{\mathrm{b}}\end{array}$ & $\mathrm{p}$ value \\
\hline Serum albumin & -0.5958 & $0.55(0.33-0.93)$ & 0.0246 \\
\hline $22: 5 \mathrm{n}-3$, weight $\%$ & -0.3545 & $0.70(0.51-0.97)$ & 0.0334 \\
\hline $\begin{array}{c}\text { Total saturated fatty } \\
\text { acids, weight } \%\end{array}$ & 0.01171 & $1.01(1.00-1.02)$ & 0.0258 \\
\hline
\end{tabular}

a The final model included ethnicity, systolic blood pressure and pulse pressure, serum albumin, creatinine, ferritin, and phosphorus, a history of coronary artery disease or myocardial infarction, stroke, and congestive heart failure, angiotensin-converting enzyme inhibitor, angiotensin receptor blockers, and statin use, and 18:3 n-3, 20:4 n-6, 22:4 n-6, 22:5 n-6, 22:5 n-3, $22: 6 n-3$, total saturated fatty acids, and total monounsaturated fatty acids.

${ }^{b}$ Increase or decrease per unit of the variable. However, for fatty acids the odds ratio reflects $0.1 \%$ increases or decreases. 
Table 4. Variables associated with odds of sudden cardiac death in the first year of hemodialysis in a final model ${ }^{\mathrm{a}}$ that included serum phospholipid fatty acids

\begin{tabular}{llll}
\hline Variable & Coefficient & $\begin{array}{l}\text { Odds ratio } \\
(95 \% \mathrm{CI})^{\mathrm{b}}\end{array}$ & p value \\
\hline Pulse pressure, mm Hg & -0.0358 & $0.96(0.93-1.00)$ & 0.0473 \\
Serum albumin, g/dl & -0.5267 & $0.59(0.36-0.98)$ & 0.0422 \\
22:5 n-3, weight \% & -0.1978 & $0.82(0.96-0.98)$ & 0.0254 \\
\hline
\end{tabular}

a The final model included ethnicity, systolic blood pressure and pulse pressure, serum albumin, cholesterol, ferritin, and phosphorus, a history of coronary artery disease or myocardial infarction, chronic obstructive pulmonary disease, stroke, and congestive heart failure, use of angiotensin-converting enzyme inhibitors, angiotensin receptor blockers, and statins, diabetes as a cause of end-stage renal disease, and phospholipid fractions of 20:4 n-6, 22:5n-3, 22:6n-3, and total monounsaturated fatty acids.

b Increase or decrease per unit of the variable. However, for fatty acids the odds ratio reflects $0.1 \%$ increases or decreases.

congestive heart failure, atrial fibrillation, liver disease, lipid disorders, cancer, anemia, chronic obstructive pulmonary disease); systolic blood pressure and pulse pressure; medication use [angiotensin-converting enzyme inhibitors, angiotensin receptor blockers, $\beta$-blockers, aspirin, and HMG-CoA reductase inhibitors (statins)], and predialysis serum biochemical indices (albumin, creatinine, ferritin, phosphorus, potassium, calcium, glucose, total cholesterol, alkaline phosphatase, parathyroid hormone, hemoglobin, white blood cells). The covariates were chosen either because there is evidence to suggest that they play a role in sudden cardiac death risk or a reasonable clinical concern that they may. We chose to be as comprehensive as possible in terms of including all families of fatty acids while focusing particular attention on the fatty acids that have previously been implicated in cardiovascular and sudden cardiac death events (i.e. polyunsaturated fats). The cross-validation method was used to tune the parameter selections. After running the preliminary variable selection, we then refitted a final logistic model that included only covariates with non-zero coefficients. We also performed a similar model selection with sudden cardiac death as the response variable but replaced the serum total fatty acids with their corresponding serum fatty acid phospholipid fractions (model 2). Descriptive analyses were performed using SAS 9.3 (Cary, N.C., USA). The logistic models with variable selection were performed using GLMNET package (cv.glmnet) in $\mathrm{R}$ (2-14-0).

\section{Results}

Four hundred patients were available in the complete patient cohort. Clinical characteristics of the combined study cohort are shown on table 1 . The cohort was similar to the overall US hemodialysis population in terms of the following major demographic and clinical characteristics [30]: age (study cohort vs. US population: 66 vs. 63 years), gender ( 58 vs. $56 \%$ male), race ( 31 vs. $32 \%$ black), ethnicity (12 vs. $13 \%$ Hispanic), mean body mass index (26 vs. 29 ), cause of end-stage renal disease ( 47 vs. $45 \%$ due to diabetes), and initial type of vascular access ( 55 vs. $63 \%$ starting with dialysis catheter). Table 2 describes the serum fatty acid profile for the study patients. The most common fatty acids included palmitic acid (16:0), oleic acid (18:1 n-9), and linoleic acid (18:2 n-6), all of which are abundant in the processed foods of the Western diet. The amounts of LCn-3 PUFA were noticeably low compared to other populations [23]. Of note, no trans fats were detected in appreciable amounts.

As described in table 3, model 1 identified 3 independent variables that were significantly associated with sudden death risk during the first year of hemodialysis. A $1 \mathrm{~g} / \mathrm{dl}$ increase in serum albumin was associated with a $45 \%$ reduction in the odds of sudden cardiac death and every $0.1 \%$ increase in total serum $22: 5 n-3$ levels was associated with a $30 \%$ reduction. In contrast, a $0.1 \%$ increase in total serum saturated fatty acid levels was associated with a $1 \%$ increase in the odds. In model 2 , serum albumin $(1 \mathrm{~g} / \mathrm{dl}$ increase reduced the odds by $41 \%)$ and $22: 5 \mathrm{n}-3$ ( $0.1 \%$ increase was associated with $18 \%$ reduction in odds) remained as significant variables in the model, with pulse pressure also being inversely associated with sudden cardiac death (1 mm Hg was linked to $4 \%$ reduction in odds) (table 4 ).

\section{Discussion}

In this study of a large representative cohort of US incident hemodialysis patients, we identified several variables that were significantly associated with the risk of sudden cardiac death during the high-risk first year period on hemodialysis. These included serum albumin, pulse pressure, as well as the LCn-3 PUFA 22:5 n-3 and total saturated fatty acids. This is the first time that fatty acids have been included in an analysis of this type, and the fact that they were among the very few factors to be associated with the outcome of interest highlights the potential importance of dietary intake on hemodialysis patient outcomes.

Previously identified risk factors for sudden cardiac death in hemodialysis patients include age $[5,7,8]$; race [8]; systolic and diastolic blood pressure $[3,5]$; markers of cardiac injury and electrophysiology (brain natriuretic peptide, troponin $\mathrm{T}$, left ventricular ejection fraction, 
short TT interval on electrocardiogram) $[3,10]$; risk factors for or a history of cardiovascular disease (congestive heart failure, coronary artery disease, diabetes mellitus, peripheral vascular disease, atrial fibrillation) $[4,5,7,8$, 11]; baseline electrolyte derangements (hypokalemia, hyperkalemia) $[4,8,11]$; aspects of the dialysis procedure (solute clearance, mode of hemodialysis, more aggressive ultrafiltration, timing of dialysis, dialysis catheters, low potassium and calcium dialysate baths) $[4-6,10,11]$; medications ( $\beta$-blockers, amiodarone) $[4,10]$, and biochemical markers of illness (serum creatinine, alkaline phosphatase levels, the state of 'wasting', C-reactive protein, interleukin-6) $[6-9,11]$. All these variables were identified in studies of prevalent hemodialysis patients, with the exception being the study by Parekh et al. [8] which reported that blood inflammatory markers were associated with risk of sudden cardiac death in a cohort of incident peritoneal and hemodialysis patients.

Our analysis involved one model that included individual serum total fatty acids and another that included the serum phospholipid fraction of these fatty acids. We did this because while serum total fatty acids are less cumbersome to measure the serum phospholipid fraction may better reflect the fatty acids in heart cell membranes that mediate ion channels and electrical conduction [31]. In fact, it is not known which fraction of blood fatty acids is the best predictor of patient outcomes, so we presented both models. Our study confirms that serum albumin, a powerful marker of illness and inflammation [32], is also a strong and robust indicator of sudden cardiac death risk as it was significant in both models. Indeed, inflammation is an important component in the pathogenesis of atherosclerotic disease which explains why other markers of inflammation like C-reactive protein have been associated with sudden cardiac death in non-dialysis populations [33].

There exists a large literature on the protective effects of LCn-3 PUFA on sudden cardiac death [34]. Putative mechanisms include effects on cell membrane structure and function, ion channels and electrophysiology, and eicosanoid production. In this study, a higher level of the blood LCn-3 PUFA 22:5 n-3 (DPA) was associated in both models with a markedly lower risk of sudden cardiac death. No association was observed with the two other LCn-3 PUFA, EPA and DHA. In fact, the anti-arrhythmic and other physiologic effects of DPA have been highly understudied relative to EPA and DHA [35]. Since nearly all clinical studies of LCn-3 PUFA with cardiovascular endpoints used fish oil - which is comprised of EPA, DPA, and DHA - it is possible that DPA has ben- eficial effects independent of EPA and DHA. However, because the metabolism of DPA is closely linked to that of EPA and DHA (i.e. it is partially derived from the same dietary source, partly synthesized from and retroconverted back to EPA via the Sprecher pathway, and partially converted to DHA) [36], it is difficult to clearly differentiate the individual effects of each LCn-3 PUFA on our outcome of interest. In a recent published study, we observed that DPA and DHA, but not EPA, were each independently and inversely associated with risk of sudden cardiac death [22]. Our present findings validate these previous observations by confirming that LCn-3 PUFA are truly independent risk factors for sudden cardiac death. They also expand upon the results by examining the odds of sudden cardiac death for a host of additional risk factors.

Because blood levels of all three LCn-3 PUFA are modifiable by diet in hemodialysis [37] patients, it may be possible to reduce the risk of sudden cardiac death and perhaps other cardiovascular outcomes by supplementing hemodialysis patients with fish oil. Indeed, as we have previously reported, US hemodialysis patients are an especially good population to supplement because their baseline levels are very low [23] and the benefits of supplementation are inversely related to baseline levels [38]. We therefore look forward to this hypothesis being tested in a rigorous manner. Of note, fish is the best dietary source for LCn-3 PUFA, though it contains relatively less DPA than the others [39]. In fact, interconversion from EPA and DHA may play a greater role in determining DPA blood levels than actual dietary intake.

Though models 1 and 2 were generally in agreement, each included one differing variable. An increase in serum total saturated fatty acids was associated with a modest rise in the odds of sudden cardiac death in model 1 but not model 2 likely because very little saturated fat is integrated into phospholipids. Of note, this is the first observation in dialysis patients linking saturated fatty acids with sudden cardiac death though they have been previously demonstrated in murine and primate models to have relatively pro-arrhythmic effects $[40,41]$. As suggested by others in the general population [42], confirmation of this finding would support revising current dietary guidelines for dialysis patients by recommending the replacement of saturated fats with LCn-3 PUFAs.

We also found that pulse pressure was a predictive factor in model 2 but not model 1, though the coefficients and odds ratios trended in a similar manner. The reason for this is not clear. In the general population, a greater pulse pressure typically reflects sclerosis of blood vessels
16

Am J Nephrol 2013;38:12-18 DOI: $10.1159 / 000351764$
Friedman/Yu/Denski/Tamez/Wenger/ Thadhani/Li/Watkins 
and is therefore an indicator of vascular disease. A higher pulse pressure has also been associated with greater risk in hemodialysis patients [43], in contrast to what we observed where it had a marginally protective effect. We postulate that this is because in our cohort a lower pulse pressure simply represents greater severity of illness. In fact, the relationship appears to be partly dependent on systolic blood pressure because when we remove systolic pressure from the model the pulse pressure becomes nonsignificant $(\mathrm{p}=0.09)$.

Our study has a number of limitations. Not all clinical markers of cardiac function were available nor did we have information on dialysis bath composition, variables that could - but have not yet been proven to - play a role in influencing outcomes. Because it is an observational trial we cannot impute causality. We also cannot exclude the possibility of residual confounding. However, the effects of LCn-3 PUFA on cardiac electrophysiology are well established [44] so our findings are supported by the scientific literature. While there is always a possibility that some of the outcomes were misclassified and not related to sudden cardiac death, this would have supported the null hypothesis and weakened the associations we observed. We cannot exclude the possibility that the nonfasting state in which the blood samples were taken could have influenced the findings. However, the fact that the model including serum phospholipid content - which reflects longer-term dietary intake - had similar findings to the model using total serum content suggests that our findings were not heavily influenced by this factor. Triglyceride levels, which may reflect dietary fat intake, were not available for analysis. Finally, in this analysis fatty ac- ids were measured in serum and not erythrocytes. Harris [45] derived the omega-3 index, which is the sum of erythrocyte EPA and DHA, to predict cardiovascular outcomes like sudden cardiac death. While we were not able to calculate the omega-3 index, it has never actually been validated in the dialysis population.

Our study also had strengths. It is the first nationally representative cohort of incident patients to be studied for insights into sudden cardiac death. It also included a large array of baseline characteristics and variables and is the first to include blood fatty acid levels.

In conclusion, we observed that baseline serum 22:5 $\mathrm{n}-3$ levels and serum albumin are strongly and inversely related to the odds of sudden cardiac death over the first year of hemodialysis, while serum saturated fatty acid levels and pulse pressure were positively associated with this outcome. Because blood fatty acid levels are modifiable by changes in dietary intake, our findings raise the possibility that dietary interventions may lower sudden cardiac death rates in the hemodialysis population.

\section{Acknowledgements}

A.N.F. was supported by funding from the National Institutes of Health (DK084403) and the National Kidney Foundation. R.T. is supported by funding from the National Institutes of Health (DK094872, HL112746).

\section{Disclosure Statement}

R.T. is a consultant to Fresenius Medical Care North America.

\section{References}

1 US Renal Data System, USRDS 2012 Annual Data Report: Atlas of End-Stage Renal Disease in the United States. Bethesda, National Institutes of Health, National Institute of Diabetes and Digestive and Kidney Diseases, 2012.

-2 Drechsler C, Meinitzer A, Pilz S, Krane V, Tomaschitz A, Ritz E, Marz W, Wanner C: Homoarginine, heart failure, and sudden cardiac death in haemodialysis patients. Eur J Heart Fail 2011;13:852-859.

3 Wang AY, Lam CW, Chan IH, Wang M, Lui SF, Sanderson JE: Sudden cardiac death in endstage renal disease patients: a 5-year prospective analysis. Hypertension 2010;56:210-216.

-4 Bleyer AJ, Hartman J, Brannon PC, ReevesDaniel A, Satko SG, Russell G: Characteristics of sudden death in hemodialysis patients. Kidney Int 2006;69:2268-2273.
5 Karnik JA, Young BS, Lew NL, Herget M, Dubinsky C, Lazarus JM, Chertow GM: Cardiac arrest and sudden death in dialysis units. Kidney Int 2001;60:350-357.

-6 Pun PH, Lehrich RW, Honeycutt EF, Herzog CA, Middleton JP: Modifiable risk factors associated with sudden cardiac arrest within hemodialysis clinics. Kidney Int 2011;79:218227.

7 Shastri S, Tangri N, Tighiouart H, Beck GJ, Vlagopoulos P, Ornt D, Eknoyan G, Kusek JW, Herzog C, Cheung AK, Sarnak MJ: Predictors of sudden cardiac death: a competing risk approach in the hemodialysis study. Clin J Am Soc Nephrol 2012;7:123-130.
${ }_{8}$ Parekh RS, Plantinga LC, Kao WH, Meoni LA, Jaar BG, Fink NE, Powe NR, Coresh J, Klag MJ: The association of sudden cardiac death with inflammation and other traditional risk factors. Kidney Int 2008;74:1335-1342.

9 Drechsler C, Grootendorst DC, Pilz S, Tomaschitz A, Krane V, Dekker F, Marz W, Ritz E, Wanner C: Wasting and sudden cardiac death in hemodialysis patients: a post hoc analysis of 4D (Die Deutsche Diabetes Dialyse Studie). Am J Kidney Dis 2011;58:599-607.

-10 Jadoul M, Thumma J, Fuller DS, Tentori F, Li Y, Morgenstern H, Mendelssohn D, Tomo T, Ethier J, Port F, Robinson BM: Modifiable practices associated with sudden death among hemodialysis patients in the dialysis outcomes and practice patterns study. Clin J Am Soc Nephrol 2012;7:765-774. 


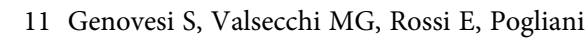
D, Acquistapace I, De Cristofaro V, Stella A, Vincenti A: Sudden death and associated factors in a historical cohort of chronic haemodialysis patients. Nephrol Dial Transplant 2009;24:2529-2536.

-12 Chan KE, Maddux FW, Tolkoff-Rubin N, Karumanchi SA, Thadhani R, Hakim RM: Early outcomes among those initiating chronic dialysis in the United States. Clin J Am Soc Nephrol 2011;6:2642-2649.

-13 Dietary supplementation with $n-3$ polyunsaturated fatty acids and vitamin $\mathrm{E}$ after myocardial infarction: Results of the GISSI-Prevenzione trial. Gruppo Italiano per lo Studio della Sopravvivenza nell'infarto miocardico. Lancet 1999;354:447-455.

14 Burr ML, Fehily AM, Gilbert JF, Rogers S, Holliday RM, Sweetnam PM, Elwood PC, Deadman NM: Effects of changes in fat, fish, and fibre intakes on death and myocardial reinfarction: diet and reinfarction trial (DART). Lancet 1989;i:757-761.

-15 Gissi-HF Investigators, Tavazzi L, Maggioni AP, et al: Effect of $n-3$ polyunsaturated fatty acids in patients with chronic heart failure (the GISSI-HF trial): a randomised, doubleblind, placebo-controlled trial. Lancet 2008; 372:1223-1230.

16 Yokoyama M, Origasa H, Matsuzaki M, Matsuzawa Y, Saito Y, Ishikawa Y, Oikawa S, Sasaki J, Hishida $\mathrm{H}$, Itakura $\mathrm{H}$, Kita $\mathrm{T}$, Kitabatake A, Nakaya N, Sakata T, Shimada K, Shirato K: Effects of eicosapentaenoic acid on major coronary events in hypercholesterolaemic patients (JELIS): a randomised open-label, blinded endpoint analysis. Lancet 2007; 369:1090-1098.

$\checkmark 17$ Kromhout D, Giltay EJ, Geleijnse JM, Alpha Omega Trial Group: n-3 fatty acids and cardiovascular events after myocardial infarction. N Engl J Med 2010;363:2015-2026.

-18 The ORIGIN Trial Investigators, Bosch J, Gerstein HC, et al: n-3 fatty acids and cardiovascular outcomes in patients with dysglycemia. N Engl J Med 2012;367:309-318.

19 Rauch B, Schiele R, Schneider S, Diller F, Victor N, Gohlke H, Gottwik M, Steinbeck G, Del Castillo U, Sack R, Worth H, Katus H, Spitzer W, Sabin G, Senges J: OMEGA, a randomized, placebo-controlled trial to test the effect of highly purified omega- 3 fatty acids on top of modern guideline-adjusted therapy after myocardial infarction. Circulation 2010;122:2152-2159.

20 Galan P, Kesse-Guyot E, Czernichow S, Briancon S, Blacher J, Hercberg S, SU.FOL.OM3 Collaborative Group: Effects of B vitamins and omega- 3 fatty acids on cardiovascular diseases: a randomised placebo controlled trial. BMJ 2010;341:c6273.
21 Burr ML, Ashfield-Watt PA, Dunstan FD, Fehily AM, Breay P, Ashton T, Zotos PC, Haboubi NA, Elwood PC: Lack of benefit of dietary advice to men with angina: results of a controlled trial. Eur J Clin Nutr 2003;57:193-200.

-22 Friedman A, Yu Z, Tabbey R, Denski C, Tamez H, Wenger J, Thadhani R, Li Y, Watkins B: Long chain $\mathrm{n}-3$ fatty acids and risk of sudden cardiac death in patients starting hemodialysis. Kidney Int 2013;83:1130-1135.

23 Friedman AN, Yu Z, Tabbey R, Denski C, Tamez H, Wenger J, Thadhani R, Li Y, Watkins BA: Low blood levels of long-chain $\mathrm{n}-3$ polyunsaturated fatty acids in US hemodialysis patients: clinical implications. Am J Nephrol 2012;36:451-458.

24 Zeleniuch-Jacquotte A, Chajes V, Van Kappel AL, Riboli E, Toniolo P: Reliability of fatty acid composition in human serum phospholipids. Eur J Clin Nutr 2000;54:367-372.

25 Department of Health and Human Services: The International Classification of Diseases, ed 9 revised, Clinical Modification: ICD-9CM. Washington, Department of Health and Human Services, 1980

26 Zheng ZJ, Croft JB, Giles WH, Mensah GA: Sudden cardiac death in the United States, 1989 to 1998. Circulation 2001;104:21582163.

27 Herzog CA, Li S, Weinhandl ED, Strief JW, Collins AJ, Gilbertson DT: Survival of dialysis patients after cardiac arrest and the impact of implantable cardioverter defibrillators. Kidney Int 2005;68:818-825.

28 Wolf M, Shah A, Gutierrez O, Ankers E, Monroy $M$, Tamez $H$, Steele D, Chang Y, Camargo CA Jr, Tonelli M, Thadhani R: Vitamin D levels and early mortality among incident hemodialysis patients. Kidney Int 2007;72:10041013.

29 Zou H, Hastie T: Regularization and variable selection via the elastic net. J R Statist Soc B 2005;67:301-320.

30 US Renal Data System, USRDS 2008 Annual Data Report: Atlas of End-Stage Renal Disease in the United States. Bethesda, National Institutes of Health, National Institute of Diabetes and Digestive and Kidney Diseases, 2008.

31 Harris W, Schacky CV: The omega-3 index: a new risk factor for death from coronary heart disease? Prev Med 2004;39:212-220.

32 Friedman AN, Fadem SZ: Reassessment of albumin as a nutritional marker in kidney disease. J Am Soc Nephrol 2010;21:223-230.

33 Mountantonakis S, Deo R: Biomarkers in atrial fibrillation, ventricular arrhythmias, and sudden cardiac death. Cardiovasc Ther 2012; 30:e74-e80.
34 Mozaffarian D, Wu JH: Omega-3 fatty acids and cardiovascular disease: effects on risk factors, molecular pathways, and clinical events. J Am Coll Cardiol 2011;58:2047-2067.

35 Mozaffarian D, Wu JH: (n-3) fatty acids and cardiovascular health: are effects of EPA and DHA shared or complementary? J Nutr 2012; 142:614S-625S.

36 Sprecher H: The roles of anabolic and catabolic reactions in the synthesis and recycling of polyunsaturated fatty acids. Prostaglandins Leukot Essent Fatty Acids 2002;67:79-83.

37 Saifullah A, Watkins BA, Saha C, Li Y, Moe SM, Friedman AN: Oral fish oil supplementation raises blood omega-3 levels and lowers C-reactive protein in haemodialysis patients - A pilot study. Nephrol Dial Transplant 2007;22:3561-3567.

38 Mozaffarian D, Rimm EB: Fish intake, contaminants, and human health: evaluating the risks and the benefits. JAMA 2006;296:18851899.

39 Mozaffarian D, Wu JH: Omega-3 fatty acids and cardiovascular disease: effects on risk factors, molecular pathways, and clinical events. J Am Coll Cardiol 2011;58:2047-2067.

40 McLennan PL, Bridle TM, Abeywardena MY, Charnock JS: Dietary lipid modulation of ventricular fibrillation threshold in the marmoset monkey. Am Heart J 1992;123:15551561.

41 McLennan PL: Relative effects of dietary saturated, monounsaturated, and polyunsaturated fatty acids on cardiac arrhythmias in rats. Am J Clin Nutr 1993;57:207-212.

42 Chiuve SE, Rimm EB, Sandhu RK, Bernstein AM, Rexrode KM, Manson JE, Willett WC, Albert CM: Dietary fat quality and risk of sudden cardiac death in women. Am J Clin Nutr 2012;96:498-507.

43 Klassen PS, Lowrie EG, Reddan DN, DeLong ER, Coladonato JA, Szczech LA, Lazarus JM, Owen WF Jr: Association between pulse pressure and mortality in patients undergoing maintenance hemodialysis. JAMA 2002;287: 1548-1555.

44 London B, Albert C, Anderson ME, Giles WR, Van Wagoner DR, Balk E, Billman GE, Chung M, Lands W, Leaf A, McAnulty J, Martens JR, Costello RB, Lathrop DA: Omega-3 fatty acids and cardiac arrhythmias: prior studies and recommendations for future research: a report from the national heart, lung, and blood institute and office of dietary supplements omega -3 fatty acids and their role in cardiac arrhythmogenesis workshop. Circulation 2007; 116:e320-e335.

45 Harris WS: The omega-3 index: clinical utility for therapeutic intervention. Curr Cardiol Rep 2010;12:503-508. 